\title{
Factors Associated with the Choice of Nursing Profession among First Year Students at Consolata Nkubu School of Nursing, Meru, Kenya
}

\author{
Article by Catherine Joan Kawira Mundi \\ Nursing, Texila American University, Kenya \\ E-mail: jkawiramundi@gmail.com
}

\begin{abstract}
The study was carried out between March and August 2017.The purpose of the study was to determine factors associated with choice of nursing profession among first Year students at Consolata Nkubu School of Nursing, Meru County, Kenya. The study adopted a cross-sectional design. The target population consisted of October 2016 and April 2017 classes. The total population during the year was 263 students. Census as a sampling method was used owing to the small sample population which was only 77 respondents'. 71 Self-administered questionnaires were distributed to the respondents who met the inclusion and exclusion criteria and 4 class representatives (Key informant) were interviewed using a checklist. The study reviewed that Majority of the students who joined the training were positive about nursing. A few students did not like nursing and were forced to join the profession. The result showed many students have changed their priorities and have settled on nursing profession after the introduction to the nursing curriculum. Given a second chance most (90\%) would still choose nursing as their career of choice. The researcher realized the need to sensitize the pupils and secondary school students on nursing profession through the media, career guidance and volunteer works to healthcare facilities. Generally the student nurses neither considered factors like well-paying career as the priority nor related to the occupation of the parents rather the desire to serve patients well was the greatest expectation after completing the course followed by advancing in the profession and desire to get a good job.
\end{abstract}

Keywords: Nursing, Profession, nurse, career, choice, associated Factors.

\section{Introduction}

The purpose of the study was to determine the factors associated with choice of nursing profession among the first year students pursuing nursing at Consolata Nkubu School of Nursing. Career has been considered as a profession which one trains and undertakes as permanent calling that entails activities and experiences encountered by an individual. Tomey and Alligood (1998), highlights that nursing as a unique function if the nurse is to assist the individual, sick or well, in the performance of those activities contributing to health or its recovery (or to peaceful death) that he would perform unaided if he had the necessary strength, will or knowledge.

Nursing education is the theoretical and practical training that is provided to nurses with the purpose of preparing them for the duties as nursing care professionals by nurses who are qualified and experienced for educational tasks (Allen, 2006).

Career choice entails a huge decision and it can be daunting. Paul (1996) clearly explains that career choices may be more difficult today than at any time in history, bearing in mind that there is infinitely more to choose from, and the levels of expectation are rising every other day. In fact, career choice involves life's decisions because it determines one's fulfillment, future happiness, income, choice of friends, dressing code, influence in society and the amount of risk to which a person is exposed to, just like a life partner and therefore it should not be a trial and error exercise.

Despite the increasing global workforce supply and demand as stated by The International council of nurses (WHO 2006 and Imison et al., 2009), there also exists a worldwide shortage of nurses in comparison with the required services (Attree et al., 2011). Therefore, it is understandable that most of the students are often not certain of their preference in choosing career choice, even in high school.

In reality, the shortages of nurses is experienced internationally so some motivating factors must be put in place for the crucial and satisfactions of performance in the chosen career, thus Law and Arthur (2003) shares a strong feeling that extrinsic factors such as parents, teachers, counselors, significant others, social influence, high salary and mass media and intrinsic pressures such as interest, ability, 
values altruistic reasons, physique and sex are also associated factors (MkhizeandNzimande.2007). According to the experience and the views of the researcher, nursing profession is filled with countless personal as well as professional rewards. Students choosing career in nursing need to understand that they are bound by the profession to spend their life giving and helping others since it is one of the flexible profession in the world. Nursing being an art and a science require compassion and caring expected to promote quality of life right from birth to death. As a career, nursing involves more of science than art and so it is often viewed as a vocation. As foreseen nurses shortage will continue more than before owing to the fact that people are living longer. Considering the many choices available for nurses after training, once the nurses qualify they do not experience difficulties in finding appointment to an entry level position due to significant shortage of nurses. Nurses work in a large variety of specialties where they work independently and as part of a team to assess, plan, implement, and evaluate care.

The perception of nursing students has a great impact on their self-esteem, self-concept, recruitment, performance and retention (Clare, 2007). According to Safadi, (2011), many students choosing nursing as a profession would imagine that being a nurse is just taking care of the patients, it is a fact that knowledge of technology, paper work and more stringent standards of care are also required which compels the nurses and nursing educators to assist students in the latest developments of caring, nurturing and critical thinking as well as acquiring latest knowledge in transformation through introduction of latest technological advances in healthcare systems.

Safadi ascertains that the perception of students on deciding to choose nursing profession as their career is highly influenced by the previous ideas about the career. Studies investigating the same showed that perception of the profession at the beginning of the programme the students had the idealistic where concepts of caring, compassion and nurturing but after exposure to the clinical experiences shifted to being more technical, documentation and procedural skills that must be acquired in the course of training and practice.

A careful analysis of this situation shows that the number of students that enroll for nursing as a training course is not as high as it should be, considering the level of demand for the nurses. This study focused on the factors that associated the choice of nursing as a profession in the Consolata Nkubu School of Nursing in order to explain the unmet demand for nurses in the country. While most studies related to the establishment of factors that determine career choice have been general about an individual and students at all levels of learning, this study's focus is on the students doing their first year academic studies at the Consolata Nkubu School of Nursing. The fact that the focus group is in their first year of study would go a long way towards getting factors that are academic-level specific when it comes to making conclusions about factors that influence career choice. The study will also come up with suggestions to improve quality nursing among newly qualified nurses as it is a concern for most of the administrators, owing to the fact that some of those joining nursing have different intentions or are pushed to do so, making it difficult to offer quality care to the patients especially the newly qualified nurses. An explanation of the choice of nursing as a profession among the students would go a long way into triggering an increase in the number of students pursuing nursing through careful strategic planning informed by the findings of this study.

Initially the respondents thought that nursing was a career with promising opportunities for advancement (27\%), was an interesting and exciting career (24\%), and provided availability of jobs (23\%), giving medicine and injections (15\%) while just a small percentage 3\% and $1 \%$ respectively thought that it was a well-paying job and a dirty job. On the contrary some felt that they chose nursing because they did not have any other opportunity and at the same time some were forced to choose nursing and given a chance would shift to another career of their choice. Interesting enough a few respondents said nursing was a vocation / calling not just a career.

\section{Methods}

\section{Participants}

The target population in the study included a total of 77 first year students' pursuing nursing at Consolata Nkubu School of Nursing who were admitted in October2016 and April 2017 intakes. This includes 32 male students and 45 female students. Due to inclusion and exclusion criteria, a total of 75 students, 33 male students and 42 female students participated in the study. 


\section{Materials}

A three page questionnaire with well elaborated instructions for the participants was prepared and used for self-administration by the respondents and interview of the Key informants.

The respondents were briefed about the purpose of the study following an informed consent they were issued with numbered questionnaires. The key informants who included four class representatives, two male and two female students were informed about the intension of the interview. They were assured of the privacy of the information that was to be recorded through a mobile phone; they all agreed to take the process freely. For the purpose maintaining confidentiality and privacy they were given numbers as participant one to four. The interview took about thirty minutes.

\section{Procedure}

Permission to access the facility, students, space and equipment's was sought from the Administration of Consolata Hospital. Students were thoroughly explained and understood before agreeing to participate in the study. Students were assured of confidentiality. None of their names was to appear in any report instead identifiers were used. Census was used where 32 male students, 45 female students, among them 4 class representatives (Key informants) were interviewed. This was appropriate since the sample population was small. During data collection 71 students gathered and Self-administered structured questionnaires were distributed to them after obtaining their consent. $100 \%$ questionnaires were returned the same day. Key informants were interviewed using in one sitting and the participants give their answers without fear of intimidation or cohesion. After the process was completed, the students were thanked for their voluntary participation. Sick students were omitted in the study but were referred for attention to the relevant sections. Data from questionnaire was entered into SPSS version 18 for analysis. Descriptive statistics such percentages and fractions was used to describe the results. Presentation of the findings was done in form of tables, bar charts, pie charts and linear graphs as appropriate. The researcher used QSR International's NVivo 10 qualitative data analysis Software package for data from the key informant interviews. Data was organized and analyzed based on a theme (thematic analysis) which was developed from responses in relation to the study objectives. Findings were presented in verbatim form.

\section{Results}

Table 1. Gender of the students

\begin{tabular}{|l|l|l|}
\hline Gender & $\mathrm{n}=71$ & Percentage \\
\hline Male & 31 & $44 \%$ \\
\hline Female & 40 & $56 \%$ \\
\hline Total & 71 & $100 \%$ \\
\hline
\end{tabular}

Table 4 indicates that female were $56 \%$ while male students were $44 \%$.

Table2. Age distribution the students

\begin{tabular}{|l|l|l|}
\hline Age in years & $\mathrm{n}=71$ & percentage \\
\hline $17-23$ & 69 & $97 \%$ \\
\hline $24-29$ & 2 & $3 \%$ \\
\hline 30 and above & 0 & 0 \\
\hline Total & 71 & $100 \%$ \\
\hline
\end{tabular}

Table 2 Shows that most of the students were ranging between 17 to 23 years as presented by $97 \%$ of the respondents, while 24 to 29 years were $3 \%$ and none of the respondents was above 30 years of age. 
DOI: $10.21522 /$ TIJNR.2015.03.02.Art002

ISSN: $2520-3126$

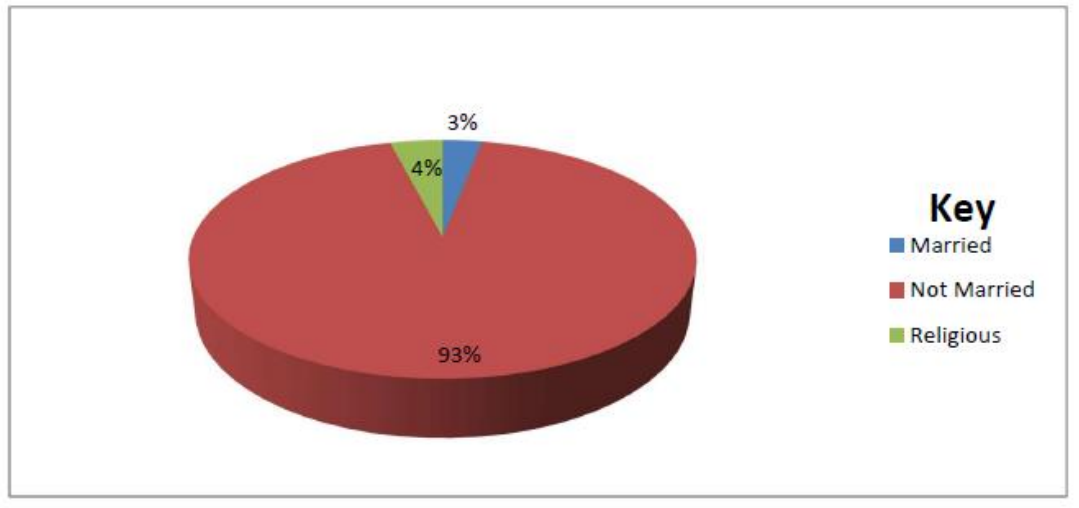

Figure 1. Marital status of the respondents

Figure 1 indicates that $93 \%$ of the respondents were not married, while $4 \%$ were religious and $3 \%$ were married.

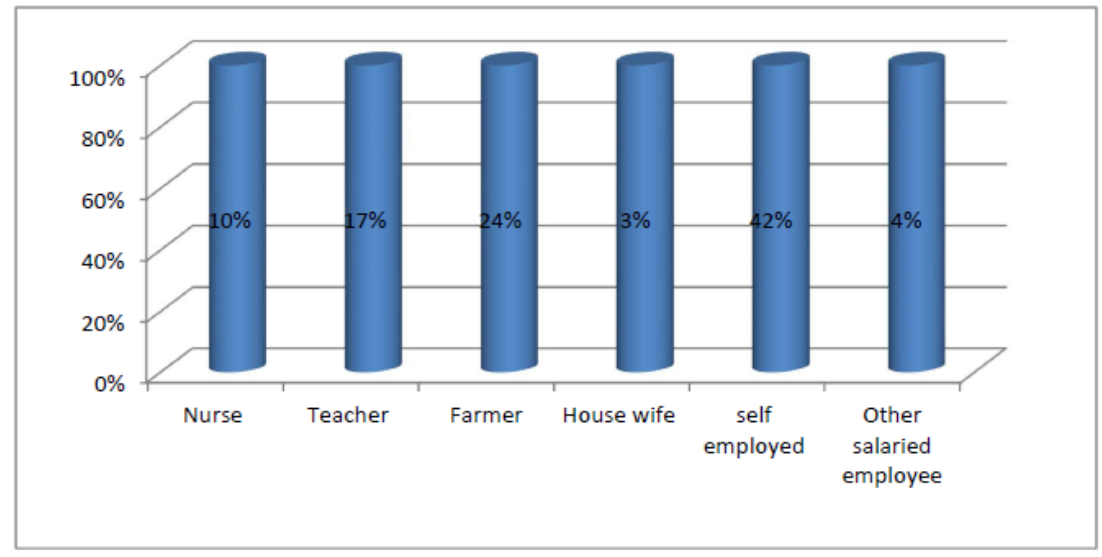

Figure 2. Occupation of the mothers

Figure 2 indicates that Mothers of 30\% (30) of the students were self-employed, 24\% (17) were farmers, $17 \%$ (12) were teachers, $10 \%$ (7) were nurses, $4 \%$ (3) fell under other salaried employees and $3 \%$ (2) were house wives.

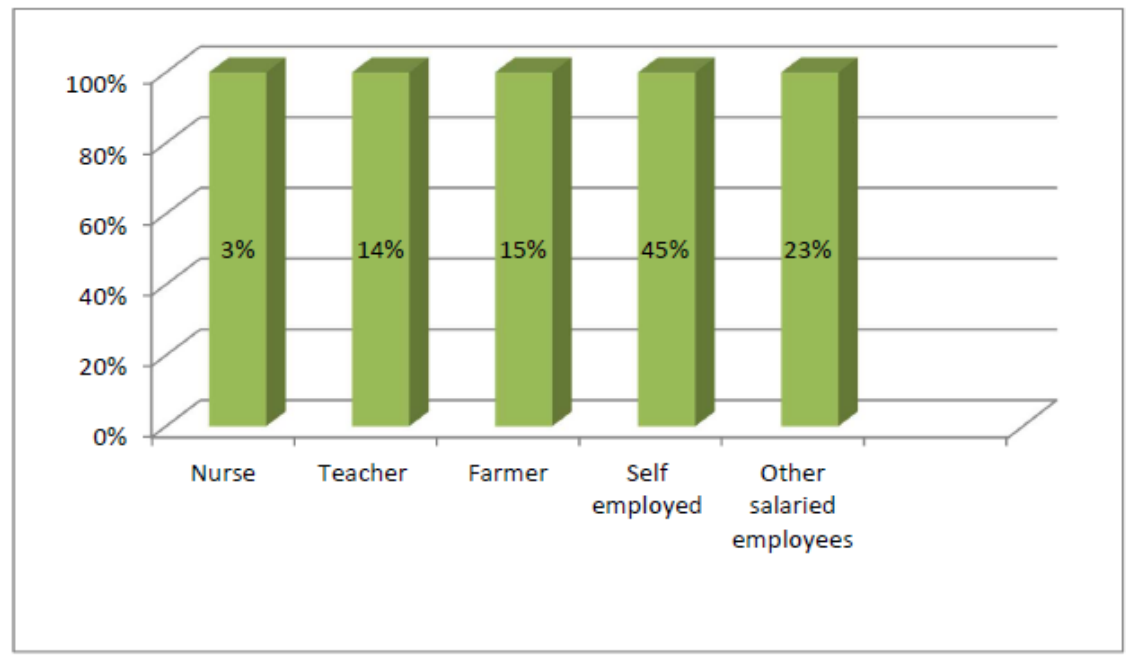

Figure 3. Occupation of the fathers

Figure 3 shows that Fathers 45\% (32) to the students were self-employed, other salaried employees were $23 \%$ (16), $15 \%$ (11) were farmers, $14 \%$ (10) were teachers and $3 \%$ (2) were nurses. 
Table 3. Initial perception of the respondents about nursing

\begin{tabular}{|l|l|l|}
\hline & $\begin{array}{l}\text { Number of } \\
\text { respondents }\end{array}$ & $\begin{array}{l}\text { Percentag } \\
\mathrm{e}\end{array}$ \\
\hline Well-paying career & 2 & $3 \%$ \\
\hline Dirty profession & 1 & $1 \%$ \\
\hline $\begin{array}{l}\text { Giving medicine and } \\
\text { injections }\end{array}$ & 11 & $15 \%$ \\
\hline Availability of jobs & 16 & $23 \%$ \\
\hline $\begin{array}{l}\text { Interesting and exciting } \\
\text { career }\end{array}$ & 17 & $24 \%$ \\
\hline Pathway for advancement & 19 & $27 \%$ \\
\hline Others & 5 & $7 \%$ \\
\hline Total & 71 & $100 \%$ \\
\hline
\end{tabular}

Table 3 reviews that varying responses were given by the respondents; pathway for advancement was the highest with $27 \%$, followed by Interesting and exciting career (24\%), availability of jobs (23\%) and $15 \%$ thought that nursing was about giving medicine and injections. On the contrary, nursing profession as a well-paying career carried only 3\% while among others some respondents thought that nursing was a calling.

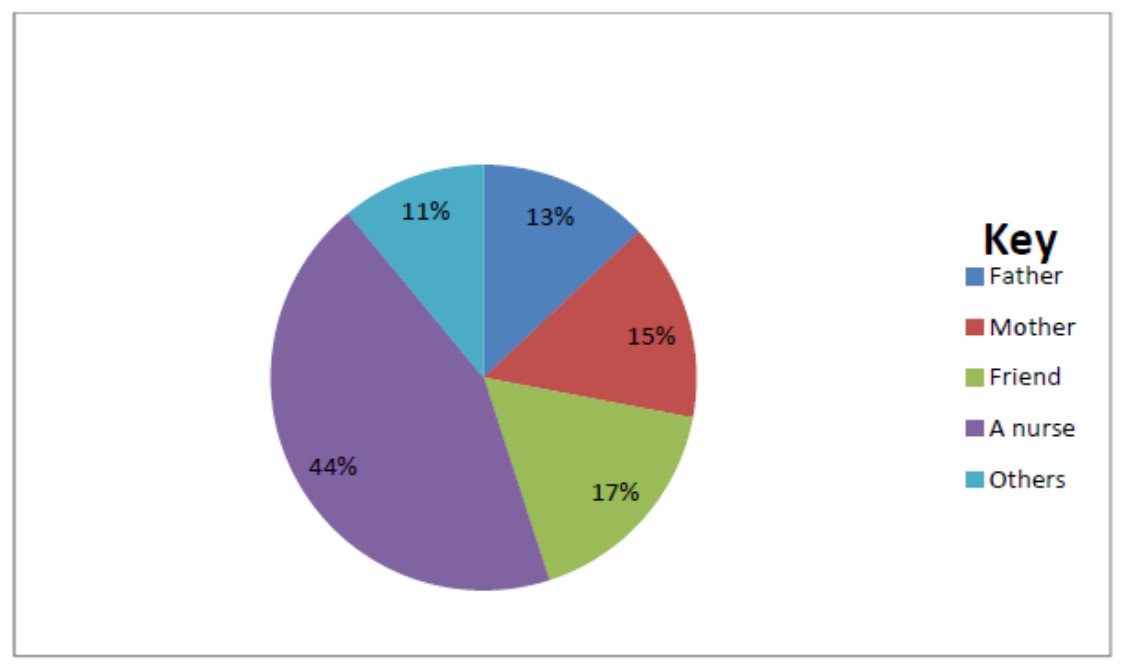

Figure 4. Role model of the respondents when choosing nursing as a profession

Figure 4 indicates that most of the role models to the students when choosing nursing were nurses accounting to $45 \%$, seconded by friends $17 \%, 15 \%$ were mothers, $13 \%$ from the fathers while $11 \%$ were from other family members.

Table 4. Factors associated with the choose nursing as your profession

\begin{tabular}{|l|l|l|l|l|}
\hline Associated factors & Yes & No & $\begin{array}{l}\text { No } \\
\text { response }\end{array}$ & Percentage \\
\hline Intrinsic & & & & \\
\hline My career of choice & $58(82 \%)$ & $5(7 \%)$ & $8(\mathrm{II} \%)$ & $100 \%$ \\
\hline $\begin{array}{l}\text { Ability to make contribution to } \\
\text { the society }\end{array}$ & $51(72 \%)$ & $5(7 \%)$ & $15(21 \%)$ & $100 \%$ \\
\hline Ability to help others & $57(80 \%)$ & $2(3 \%)$ & $12(17 \%)$ & $100 \%$ \\
\hline No other option & $3(4 \%)$ & $37(52 \%)$ & $31(44 \%)$ & $100 \%$ \\
\hline Extrinsic Factors & & & & \\
\hline Working opportunities & $42(59 \%)$ & $13(18 \%)$ & $16(23 \%)$ & $100 \%$ \\
\hline Parent(s) influence & $10(14 \%)$ & $49(69 \%)$ & $12(17 \%)$ & $100 \%$ \\
\hline Peer and friends & $10(14 \%)$ & $49(69 \%)$ & $12(17 \%)$ & $100 \%$ \\
\hline Career adviser/teacher's advise & $22(31 \%)$ & $32(45 \%)$ & $17(24 \%)$ & $100 \%$ \\
\hline
\end{tabular}


DOI: $10.21522 /$ TIJNR.2015.03.02.Art002

ISSN: $2520-3126$

\begin{tabular}{|l|l|l|l|l|}
\hline $\begin{array}{l}\text { Opportunities for advancement } \\
/ \text { promotion }\end{array}$ & $38(53 \%)$ & $19(27 \%)$ & $14(20 \%)$ & $100 \%$ \\
\hline Community respect for nurses & $35(49 \%)$ & $26(37 \%)$ & $10(14 \%)$ & $100 \%$ \\
\hline $\begin{array}{l}\text { The prestige attached to } \\
\text { profession }\end{array}$ & $37(52 \%)$ & $23(33 \%)$ & $11(15 \%)$ & $100 \%$ \\
\hline Job security & $27(38 \%)$ & $2(37 \%) 6$ & $18(25 \%)$ & $100 \%$ \\
\hline Opportunity to travel & $14(20 \%)$ & $37(52 \%)$ & $20(28 \%)$ & $100 \%$ \\
\hline
\end{tabular}

Table 4 indicates that the respondents' had a variety of choices on factors associated with the choice of nursing; career of choice was presented by (82\%), ability to help others (80\%), Ability to make contribution to the society (72\%), Working opportunities (59\%), Opportunities for advancement / promotion (53\%), prestige attached to profession (52\%) and 3\% had no other option apart from joining nursing among other choices.

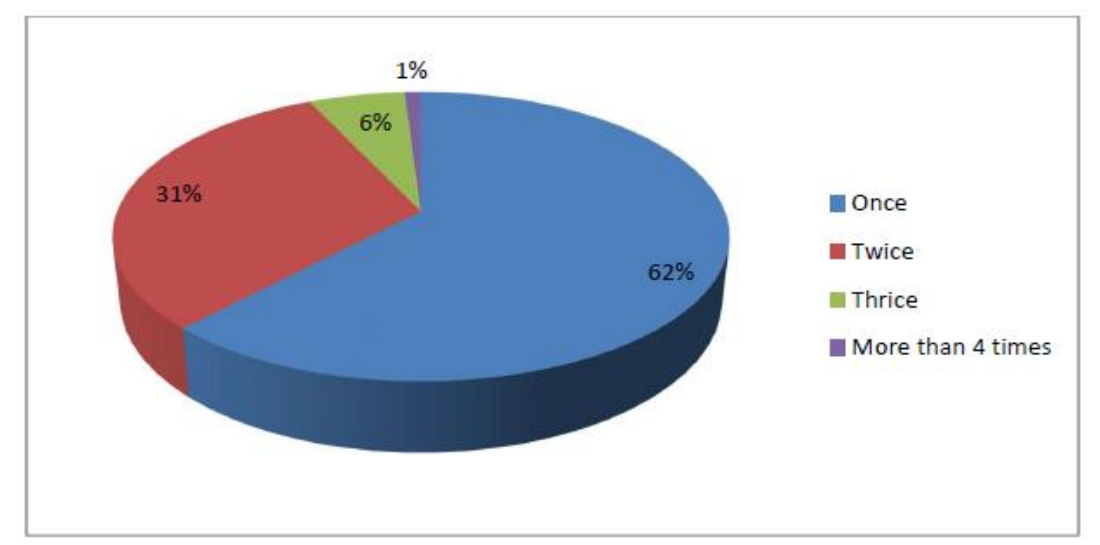

Figure 4. Trends in application for nursing before admission

Figure 4 implies that $62 \%$ of the students applied once, 31\% applied twice, 6\% applied thrice whereas $1 \%$ of the students had applied more four times.

\section{Students' source of information about nursing career}

The respondents had different sources of information about nursing some had more than one sources. Generally the sources of information were: Books and pamphlets, Social media Personal interactions with the nurse(s), Career guidance teacher, as a patient, Parents/ relatives. The most common sources among the students at Consulate Nkubu School of nursing included personal interactions with nurses with a presentation of 40 respondents $(56 \%)$ followed by parents / relatives $16(23 \%)$ and social media $12(17 \%)$. Those who knew about nursing from career guidance teacher were $7 \%$ among other presentation. $3 \%$ did not respond to the question.

\section{Perception about nursing today}

The respondents had various perceptions from what they had before joining nursing. Among the choices were; It my career of choice, I don't like it, It is interesting and exciting, Given a chance I would choose another career and Am forced to do nursing. The highest percentage (77\%) perceived nursing as their career of choice, followed by $21 \%$ who felt that nursing was exciting and interesting, the rest were presented by $1 \%$. In addition $1 \%$ took it as a pathway for advancement while $3 \%$ did not respond to the question.

\section{Expectations of respondents after completing the nursing course}

The respondents had several opinions about their expectations after completing the nursing course as follows; to get a good job, to get a high salary, to advance in my career, to start my own clinic/hospital, to serve the patients well. Most of the respondents (52\%) expect to serve the patients well, $25 \%$ to advance in career, $13 \%$ to get a job, $8 \%$ to start their own clinics/ hospitals and $2 \%$ to get a job. Other purposes were to help the needy and to serve with dignity, while $3 \%$ were non responsive. 


\section{Interview of the key informants}

The key informants' interview of four class representatives reviewed that $100 \%$ of the participants ranged between 17 to 23 years of age and none of them was married. $50 \%$ of the mothers and fathers were farmers and nurses. Apart from availability of job opportunities and nursing being an interesting and exciting career, the participants also thought nursing was a vocation or a calling.

Out of the four participants only one expressed that nursing was not the career of choice. Majority choose nursing because of the ability to make contribution to the society and to help others; working opportunities; prestige attached to the profession, job security and opportunity to travel.

Given a chance to choose a profession after joining the profession all participants would choose the same profession. $50 \%$ of the participants applied once and twice respectively.

The expectation of majority of the participant after completing the nursing course is to get a good job, advance in career and to serve the patients well

\section{Discussion}

According to International Council of Nurses (2003), Nursing has emerged to be noble profession and nurses play a major role in the healthcare sector. It is true that there is an increase in shortage of nurses all over the world thus the need to recruit more nurses.

Despite the fact that nursing is believed to be the oldest profession, Florence Nightingale is believed to have played a major role in both nursing education and a central figure in the history of nursing. She fulfilled her dream by starting Nightingale School of nursing in the year 1869 (Booth, 2002), thus nurses are valued in the community as the advocates of the patients.

The total number of respondents who participated in the research (75), 71 voluntarily filled in the questionnaires while the four class representatives (key informants) were interviewed.

It was evident that $97 \%$ of the respondents were between the 17 to 23 years of age and $93 \%$ were not married.

The total population of female respondents was $56 \%$. Compared to male who were presented by $44 \%$ the same findings were reported by Romem and Anson (2005) that nursing is a more feminine career as opposed to males. This has been the perception since the era of Florence Nightingale and has been difficult to change in the minds of many people.

The study showed that the occupation of the parents did not necessarily change the knowledge and attitude of the participants since most of the parents were self-employed as reported by the respondents; Fathers of $45 \%$ and $30 \%$ of the mother of the students were self-employed as compared to those who were nurses, $10 \%$ (7) of the mothers and only $3 \%$ of the fathers were nurses.

Initially the respondents thought that nursing was a career with promising opportunities for advancement as presented by (27\%), was an interesting and exciting career (24\%), provided availability of jobs (23\%), giving medicine and injections (15\%) while just a small percentage $3 \%$ and $1 \%$ respectively thought that it was a well-paying job and a dirty job. On the contrary some felt that they chose nursing because they did not have any other choice and at the same time some were forced to choose nursing. Interesting enough a few respondents said nursing was a vocation / calling not just a career.

Despite the fact that most of the parents were not nurses by profession most of the students had encountered nurses as their role models in choosing nursing profession as presented by $45 \%$ of the respondents among many other choices, seconded by friends (17\%).

Majority of the respondents pointed out many factors associated with their choice of nursing but the frequently chosen were; career of choice $(82 \%)$, ability to help others $(80 \%)$, Ability to make contribution to the society (72\%), Working opportunities (59\%), Opportunities for advancement /promotion (53\%), and the prestige attached to profession (52\%) among other choices. Even with different knowledge and attitude initially, given a second chance, $(90 \%)$ would still choose nursing.

It was clear that the highest percentage $(62 \%)$ were admitted after the first interview, $22 \%$ after applying twice and $1 \%$ after attempting three times.

According to the study findings, it is evident that the idea of helping others people after training plays a significant role for the students in choosing profession. The same findings were identified from several studies that indicated that students choose nursing in order to serve the patients better. 


\section{Conclusions}

It was pointed out that majority of the students learnt about nursing profession through personal interaction with a nurse and yet nurses were the role models for many students who joined nursing. Factors associated with choice of career for many students were career of choice, Ability to make contribution to the society, ability to help others, working opportunities for advancement / promotion, and the prestige attached to profession. Even with different knowledge and attitude initially, given a second chance many would still choose nursing.

Despite the fact nursing was not a career of choice for few respondents and were forced to join the profession; majority (90\%) would still choose nursing as their profession for varying reasons. Therefore the perception of nursing changed after joining the training and $77 \%$ of the respondents have settled on nursing as their career of choice, $21 \%$ as an interesting and exciting job while the other percentage feel that nursing is not their career, they don't like nursing and also were forced to do nursing.

Generally the student nurses neither considered factors like well-paying career as the priority nor related to the occupation of the parents rather the desire to serve patients well was the greatest expectation after completing the course followed by advancing in the profession and desire to get a good job.

\section{Acknowledgement}

I acknowledge all who assisted me in any way to complete this manuscript. Rev. Sr. Adelina M. Muguna and her council member for their moral and financial support ,special thanks to Dr. Joseph Mutai for expertise support all through my study, Consolata Hospital Director, Rev. Fr. Silas and all study participants in a particular first year nursing students at Consolata Nkubu School of nursing. This manuscript was a requirement for the Master in Nursing at Texila American University, God blesses the University team for assisting me to grow in my career, special thanks to the Course Coordinator Madam A. Mary Jenitta and all other Coordinators who have supported me in the course of my studies.

\section{Recommendations}

1. School teachers and counselors need to be sensitized on nursing career in order to be able to give career guidance to the young people.

2. For publicity of the profession, the nursing profession requires interaction with the media and general public.

3. The secondary school students should be given opportunities to do volunteer works the healthcare facilities to assist them cultivate positive attitude towards nursing career

4. Since the role model in choosing nursing was a nurse and the sources of information was through interaction with nurse(s), nurses should handle their career with a lot of love and dedication, when treating the patients to avoid discouraging the young people from choosing nursing.

5. Nurses also need to have educative programmers in schools for example school health services to create a positive image towards nursing among the school going students.

\section{References}

[1].Allen, M., Allison, M. M., and Stevens, S. (2006). Mapping the literature of nursing education. Journal of the Medical Library Association, 94.

[2].Attree, M., Flinkman, M., Howley, B., Lakanmaa, R-L., L ima-Basto, M., \& Uhrenfeldt, L. (2011). A review of nursing workforce policies in Five European countries: Denmark, Finland, Ireland, Portugal and United Kingdom.

[3].Booth, R.Z. (2002).The nursing shortage: A worldwide problem. Revisto Latino-Careers in Nursing. A world of opportunities (2017) 10 Reasons Why You Should Choose Nursing. Registered Nurses Association of Ontario

[4].Clara B. Wallace (2007) Nursing students' perceptions of the public image of nursing. A Dissertation Presented in Partial Fulfillment of the Requirements for the Degree Doctor of Philosophy, Capella University. Conversion among student nurses. In A Sociology of Medical Practice (Cox, C. \& Mead, A. Ed). Macmillan, London, pp.116-131. 
Texila International Journal of Nursing Volume 3, Issue 2, Dec 2017

[5].Imison C, Buchan J, Xavier S (2009). NHS Workforce Planning: Limitations and possibilities. London: The King's Fund.

[6].International Council of Nurses. (2003). Global issues in the supply and demand of nurses. SEW News January- March. Retrieved July 17, 2006.

[7].Law W, Arthur D (2003) what factors influence Hong Kong school students in their choice of a career in nursing? International Journal of Nursing Studies 40: 23-32.

[8].Matejski, M. P. (1981). Nursing education, professionalism, and autonomy: social constraints and the Goldmark Report. Advances in Nursing Science, 3(3), 17-30.

[9].Mkhize S, Nzimande S (2007) Career choices in relation to nursing. Cross-sectional descriptive study investigating the career choices of school leavers in relation to nursing and what influences these choices. Report prepared by research programme of Health Systems Trust.

[10]. Paul, S. (1996). The Top 10 Steps for Choosing a Career. Retrieved September 24, 2008, from http://topten.org/public/AB/AB6.html.

[11]. Romem P. and Anson O. (2005) Israeli men in nursing: social and personal motives. JNurs Manag 13: 173 178.

[12]. Safadi, R.R., Saleh, M.Y. M., Nassar, O.S., Amre, H. M., Froelicher, E.S., 2011. Nursing Students perceptions of nursing: a descriptive study of four cohorts. International Nursing Review oct.2011 p.p.54.

[13]. Tomey, A. M., \& Alligood, M. R. (1998). Nursing theorists and their work (p. 102). St. Louis: Mosby.

[14]. World Health Organization (2006).World Health Report: Working Together for Health [PowerPoint Slides]. 